One of the most powerful suggestions in the book is its encouragement to read the poems aloud and immerse yourself in its words. This harnesses the power not only of the words themselves but also of your own imagination. Recent findings from neuroscience support this - FMR scans show that the simple act of just imagining compassion activates the soothing and affiliation component of the emotion regulation system of the brain.'

The poems are well chosen to illustrate alternatives to our present mood. An afterword by Mark Williams linking the use of the book to the practice of mindfulness is a very satisfying coda to the whole experience.

All proceeds from the sales will be donated to ReLit, the campaign to alleviate stress and other mental health conditions through mindful reading. All doctors and patients can benefit from 'dipping into' this book and I recommend it for all of us who are facing difficult times during the current GP workload crisis. Every waiting room should have a copy.

http://www.relit.org.uk/

\section{Nigel Mathers,}

Head of Academic Unit of Primary Medical

Care, University of Sheffield, Samuel Fox House, Northern General Hospital, Herries Road, Sheffield; RCGP Honorary Secretary, RCGP, London.

E-mail: n.mathersđasheffield.ac.uk

DOI: 10.3399/bjgp16X687409

\section{REFERENCE}

Gilbert P. Choden. Mindful compassion London: Constable, 2013.
When Someone You Know Has Depression: Words to Say and Things to Do Susan J Noonan

Johns Hopkins University Press, 2016, PB, 160pp, E11.00, 978-1421420158

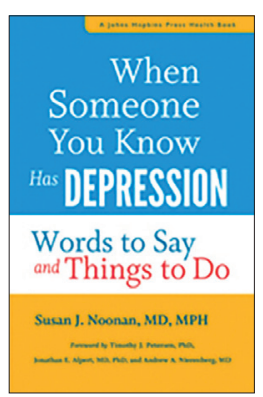

\section{RECOVERY AND RESILIENCE}

Susan Noonan is a US physician and peer specialist, who has lived experience of depression. In this brief and accessible text she provides a wealth of practical information to enable family and friends to offer help to someone who is depressed. Beginning with the epidemiology of depression, she goes on to describe symptoms and signs, and then provides valuable advice on supportive communication strategies, mental health first aid, and when and how to enlist professional help. There are particularly useful sections on warning signs for suicide, setting boundaries and maintaining one's own personal space, and how to anticipate recovery and build resilience.

Interspersed with the text, Noonan provides a set of charts and tables for use by family and friends. Some of the tables, for instance on pleasurable activities or sleep hygiene, could be a useful resource during GP consultations.

I do have some concerns. The list of resources given at the end of the book is US-based and would need to be amended for use in the UK and other countries. Noonan has a more biological and genetic orientation to depression than is warranted by existing evidence.

Her argument for the underdiagnosis of depression in men is debatable and is not balanced by discussion of the problems of overdiagnosis. I am unconvinced of the benefits of asking patients to keep a daily mood chart, as this runs the risk of encouraging preoccupation with mental symptoms.

With these caveats, I would recommend this book to family members and friends of patients who are living with severe, recurrent, or long-term depressive disorders, as a companion to my own introduction for children. ${ }^{1}$ And as well as inviting my patients to read my own blog, well becoming, I will now suggest they also follow Noonan's View from the Mist.

\section{Christopher Dowrick,}

Professor of Primary Medical Care, Institute of Psychology, Health and Society, University of Liverpool, Liverpool.

E-mail: cfdaliv.ac.uk

DOI: 10.3399/bjgp16X687421

\section{REFERENCE}

1. Dowrick C, Martin S. Can I tell you about depression? London: Jessica Kingsley Publishers, 2015.

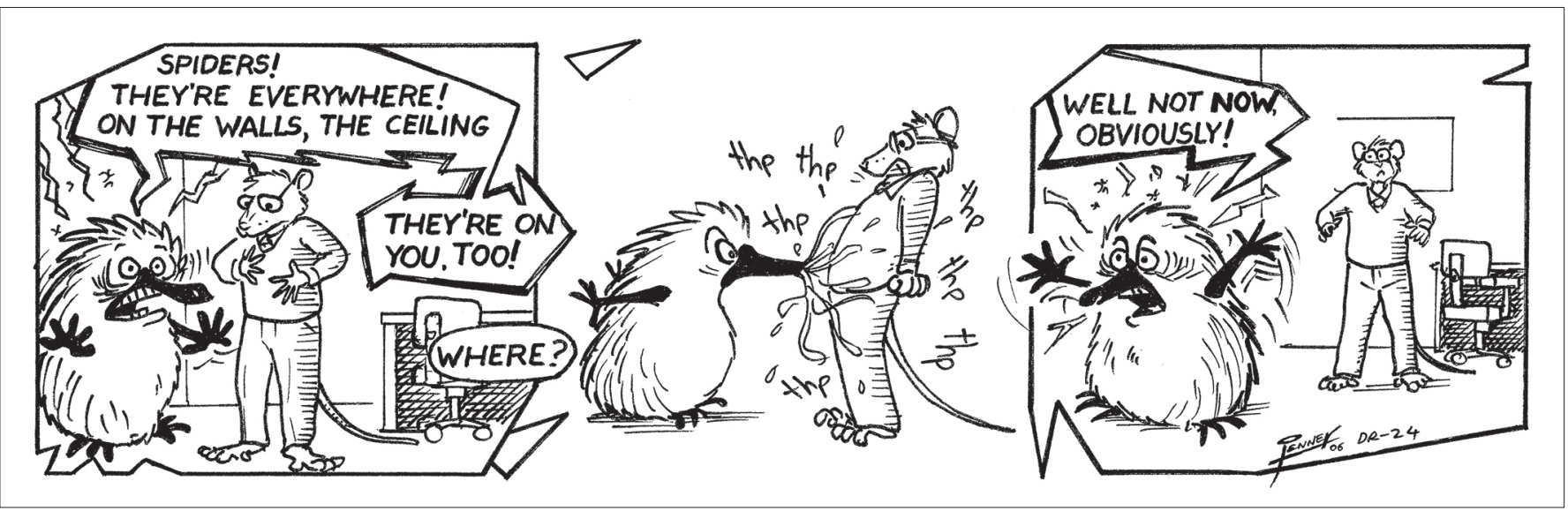

